UDK 528.711.1

\title{
MAŽŲ GREIČIŲ LĖKTUVO SPARNO AERODINAMINIŲ PARAMETRŲ SKAIČIAVIMO TIKSLUMAS
}

\author{
Egidijus Pakalnis, Jonas Stankūnas \\ Antano Gustaičio aviacijos institutas, Vilniaus Gedimino technikos universitetas, \\ Rodūnios kelias 30, LT-02187 Vilnius-38, Lietuva, \\ el. paštas: avinst@ai.vtu.lt
}

Iteikta 20050105 , priimta 20050314

\begin{abstract}
Santrauka. Pateikiami strèlinio NACA4415 profilio sparno skaičiavimo paklaidų analizès rezultatai. Šio sparno aerodinaminiai koeficientai buvo apskaičiuoti taikant sūkurio žingsnio metodą, papildytą specialiu algoritmu netiesinėms profilio charakteristikoms įvertinti. Kiekvieno sparno modelio elemento aerodinaminių koeficientu skaičiavimo paklaidos buvo nustatytos pagal (1) formulę keliamajai jègai ir (2) formulę pasipriešinimo jègai rasti. Viso sparno aerodinaminių jègų koeficientų skaičiavimo paklaidos apskaičiuotos pagal (3) ir (4) formules. Grafiškai pateikiama paklaidu priklausomybė nuo sparno atakos ir strèliškumo kampo.
\end{abstract}

Raktažodžiai: aerodinaminiai koeficientai, skaičiavimo paklaidos.

\section{Ivadas}

Aeronuotrauka - vienas iš šiuolaikinių metodų, palengvinančių kartografų darbą. Labai tiksliems didelių teritorijų žemėlapiams sudaryti atliekami topografiniai matavimai ir naudojamos iš lèktuvų ar dirbtinių palydovų darytos fotografijos. Šis metodas ypač patogus sudarant sunkiai prieinamų vietų žemèlapius. Paprastai iš skrendančio lèktuvo padaroma serija nuotraukų. Kiekviena iš ju apima apie $60 \%$ ankstesnès, tai leidžia specialiais prietaisais sudaryti stereoskopini vietovès vaizdą ir apskaičiuoti reikalingu tašku aukščius. Tam tikslui naudojami kuo stabilesnių skrydžio parametrų, lengvai valdomi nedidelių greičių lèktuvai. Šiuo atžvilgiu ypač svarbios tokio lèktuvo sparno aerodinaminès charakteristikos ir jų nustatymo metodai.

Kaip atsvara šiuolaikiniams skaičiuojamosios dujų dinamikos metodams dabar taikomi palyginti paprasti baigtinio ilgio sparno aerodinaminiu charakteristiku skaičiavimo metodai, iš pasagos formos sūkurių sudarius sparno modeli. Šie metodai tobulinami apimant vis sudètingesnius skaičiuojamojo sparno geometrijos atvejus ir aptekamo srauto sąlygas [1]. Pavieniais atvejais tokių metodu tikslumas prilygsta skaičiuojamosios dujų dinamikos metodu tikslumui [2], o taikomas sparno modelis daug paprastesnis, todèl galima greitai išanalizuoti daug ivvairiu sparno geometrijos variantu, keičiantis aptekejimo sąlygoms. Tam tikra šių metodų grupe - metodai, kuriuos taikant sparno skaičiavimams tiesiogiai remiamasi netiesinemis profiliu charakteristikomis. Šiame straipsnyje pateikiami skaičiavimo paklaidu analizès rezultatai, pritaikius toki metodą stačiakampiams ir strèliniams ivvairaus ilgmens sparnams skaičiuoti.

\section{Aerodinaminių jègų koeficientų skaičiavimo paklaidų nustatymas}

Skaičiavimui taikytas metodas ir netiesinių profilio charakteristikų ivvertinimo algoritmas plačiau aprašomas [3] šaltinyje. Sparno keliamosios jègos koeficiento skaičiavimo paklaidos priklauso nuo sparną sudarančiu profilių keliamosios jègos koeficientu tikslumo. Šie koeficientai gali būti apskaičiuojami profilių analizès metodais arba nustatomi eksperimentiniu būdu. Tokiu atveju neišreikštinès keliamosios jẻgos koeficiento skaičiavimo paklaidos vektorius:

$$
\Delta C_{l}=[b]^{-1} \cdot A
$$

čia vektorius $\boldsymbol{A}$ :

$$
\boldsymbol{A}=\left\{\sqrt{2 \cos ^{2}\left(\alpha_{s p}-\alpha_{0, p r o f}-\Delta \alpha_{0}\right)\left(\Delta C_{l}^{2}+\Delta C_{l}^{* 2}\right)}\right\},
$$

$[\boldsymbol{b}]^{-1}$ - atvirkštinè geometrinių koeficientų matrica, $\alpha_{s p}-$ sparno atakos kampas, $\alpha_{0, \text { prof }}-$ profilio nulinès keliamosios jègos atakos kampas, $\Delta \alpha_{0}-$ modelio elemento istatymo kampo korekcija, $\Delta C_{l}^{*}-$ profilio keliamosios jègos koeficientų tikslumas. Nuo iteracijų skaičiaus šis dydis nepriklauso. Profilių keliamosios jëgos koeficientų tikslumas, skaičiuojant juos X-FOIL [4] programa, taip pat pastovus ir yra lygus:

$$
\Delta C_{l}^{*}=\frac{0,5}{10^{z l}},
$$


čia $z l-X$-FOIL rezultato, naudojamo skaičiuojant sparno pjūvius $C_{l}$, ženklų skaičius po kablelio.

Neišreikštinè $\Delta C_{l}$ atžvilgiu lygtis (1) sprendžiama skaitiniais-iteraciniais metodais. Šiam sprendimui būtinas tikslumas nustatomas 10 kartų didesnis nei absoliutusis skirtumas tarp apskaičiuoto pjūvio keliamosios jègos koeficiento ir profilio keliamosios jègos koeficiento.

Sparno keliamosios jègos koeficiento skaičiavimo paklaida:

$$
\Delta C_{L}=\frac{\Delta z}{S} \sqrt{\sum\left(\Delta C_{l} \cdot c\right)^{2}}
$$

čia $\Delta z$ - modelio elemento plotis, $S$ - sparno plotas, $c-$ sparno stygos ilgis.

Pasipriešinimo jègos koeficiento skaičiavimo paklaida:

$$
\begin{aligned}
& \left(\Delta C_{d}\right)^{2}=\operatorname{tg}^{2} \alpha_{i} \cdot \Delta C_{l}^{2}+\frac{C_{l}^{2}}{\cos ^{4} \alpha_{i}} \times \\
& \times\left(\frac{2 \cdot \Delta C_{l}^{2}+\left(\Delta C_{l}^{*}\right)^{2}}{4 \pi^{2}}+\left(\Delta \alpha_{0, \text { prof }}\right)^{2}\right)+ \\
& +\Delta C_{d 0}{ }^{2},
\end{aligned}
$$

čia $\alpha_{i}-$ indukcinis atakos kampas, $C_{l}$ - elemento keliamosios jègos koeficientas, $\Delta \alpha_{0, p r o f}-$ profilio nulinès keliamosios jègos atakos kampo tikslumas, gaunamas iš eksperimentinių duomenų. Profilio koeficientus skaičiuojant pagal X-FOIL, $\Delta \alpha_{0, p r o f}=0,05^{\circ} \cdot \Delta C_{d 0}-$ profilinio pasipriešinimo jëgos koeficiento tikslumas, kuriuo pateikiami eksperimentiniai rezultatai. Nuo iteracijų skaičiaus šis dydis nepriklauso. Profilinès pasipriešinimo jègos koeficientų tikslumas skaičiuojant juos X-FOIL programa, taip pat pastovus ir yra:

$$
\Delta C_{d 0}=\frac{0,5}{10^{z d}},
$$

čia $z d-\mathrm{X}$-FOIL rezultato, naudojamo skaičiuojant sparno pjūvius $C_{d}$, ženklų skaičius po kablelio.

Sparno pasipriešinimo jègos koeficiento skaičiavimo paklaida:

$$
\Delta C_{D}=\frac{\Delta z}{S} \sqrt{\sum\left(\Delta C_{d} \cdot c\right)^{2}}
$$

\section{Strèlinio sparno skaičiavimo paklaidų analizès rezultatai}

Eksperimentinių profilių charakteristikų paklaidos (6-8 \%) labai skiriasi nuo paklaidų, gautų skaičiuojant profilio chrakteristikas pagal programą X-FOIL (apie $0,05 \%)$. Dèl šios priežasties - taikant skirtingais būdais gautas profiliu charakteristikas negalima palyginti galutiniu sparno netiesinių aerodinaminių parametru skaičiavimo paklaidų. Kadangi profilio eksperimentinių charakteristiku paklaidos nepriklauso nuo skaičiuojamojo sparno geometrijos, sparno charakteristikų skaičiavimo paklaidos buvo analizuojamos atskirai.

1 ir 2 paveiksluose pateiktos NACA4415 profilio sparno skaičiavimo paklaidos. Keliamosios jègos koeficiento skaičiavimo paklaidos mažai priklauso nuo atakos kampo: kai sparnas stačiakampis - šiek tiek mažèja, kai strèlinis - nežymiai didejja. Pasipriešinimo jëgos koeficiento skaičiavimo paklaidos didejja, didejant atakos kampui (2 pav.).

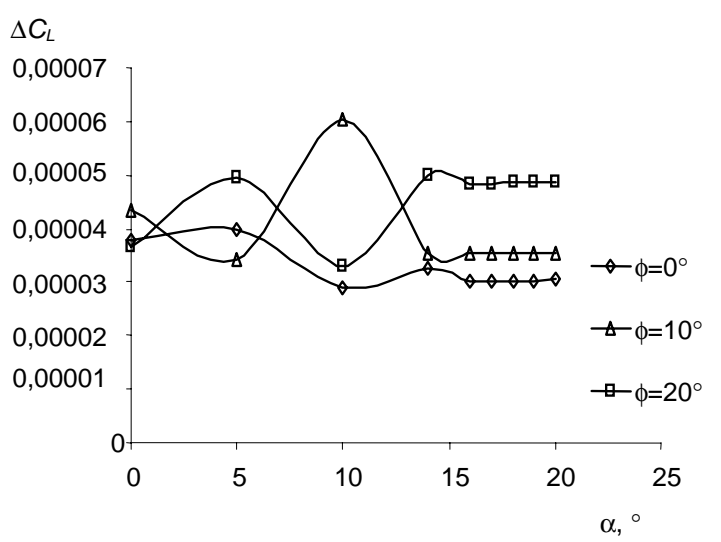

1 pav. Keliamosios jègos koeficiento skaičiavimo paklaidu priklausomybė nuo sparno strèliškumo. NACA4415 sparnas, $\mathrm{Re}=2,1 \times 10^{6}, \mathrm{AR}=6,2$

Fig 1. Calculation error of wing lift force coefficient dependence on wing sweep. NACA4415 wing $\mathrm{Re}=2,1 \times 10^{6}$, $\mathrm{AR}=6,2$

Be to, ši savybè būdinga visiems skaičiuotiems sparnams: stačiakampiams, strèliniams ir trapeciniams.

3 ir 4 paveiksluose pateikiama santykiniu skaičiavimo paklaidų priklausomybè nuo sparno strèliškumo, leidžianti ivertinti aerodinaminių sparno koeficientu pokyti, keičiantis sparno atakos kampui. Didèjant atakos kampui santykinès paklaidos mažèja.

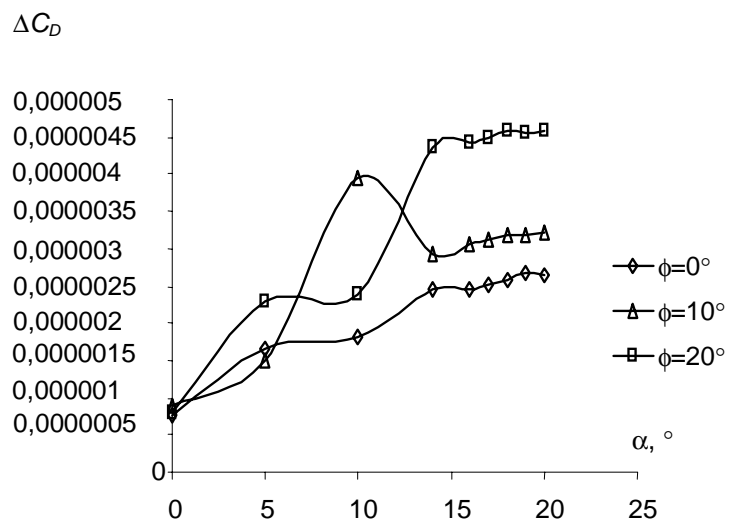

2 pav. Pasipriešinimo jẻgos koeficiento skaičiavimo paklaidu priklausomybè nuo sparno strèliškumo. NACA4415 sparnas, $\mathrm{Re}=2,1 \times 10^{6}, \mathrm{AR}=6,2$

Fig 2. Calculation error of wing drag force coefficient dependence on wing sweep. NACA4415 wing $\mathrm{Re}=2,1 \times 10^{6}$, $\mathrm{AR}=6,2$ 
Skirtingai nuo pasipriešinimo jègos keliamosios jègos koeficiento santykinès paklaidos mažèja netiesiškai, pavyzdžiui, 3 pav. pavaizduota kreivè, kuria mažiausiujų kvadratų metodu galima aproksimuoti strèlinio sparno keliamosios jègos koeficiento santykinių paklaidų taškus $\left(\phi=10^{\circ}\right)$. Analogiškai 4 paveiksle pateikta tiesé, geriausiai atitinkanti to paties sparno pasipriešinimo jègos koeficiento santykinès paklaidos taškus.

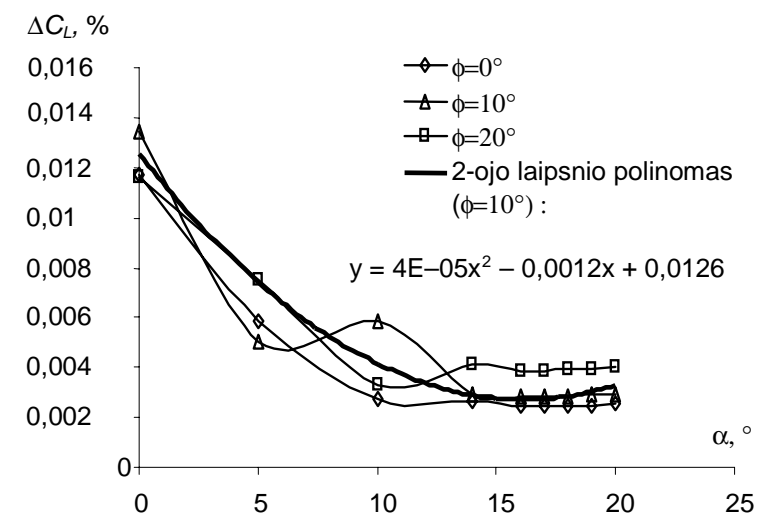

3 pav. Keliamosios jègos koeficiento santykinès skaičiavimo paklaidos priklausomybè nuo sparno strèliškumo. NACA4415 sparnas, $\mathrm{Re}=2,1 \times 10^{6}, \mathrm{AR}=6,2$

Fig 3. Relative calculation error of wing lift force coefficient dependence on wing sweep. NACA4415 wing $\operatorname{Re}=2,1 \times 10^{6}$, $\mathrm{AR}=6,2$

Didejjant atakos kampui santykinè keliamosios jègos koeficiento skaičiavimo paklaida esant tam tikram atakos kampo dydžiui pasiekia pastovią reikšmę. Kaip parodė tolesni tyrimai, šis kampas sutampa su kritiniu (arba maksimalios keliamosios jègos) skaičiuojamojo sparno atakos kampu. 3 paveiksle pavaizduoto sparno kritinis atakos kampas yra lygus $16^{\circ}$.

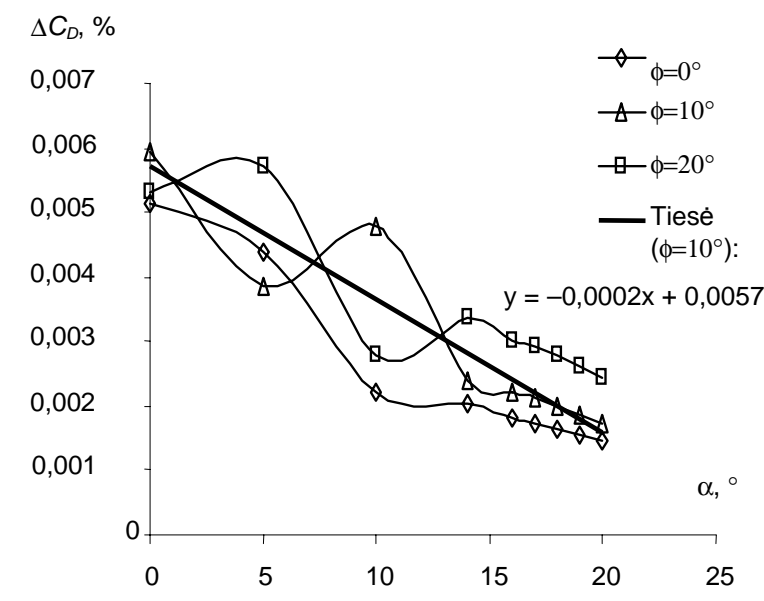

4 pav. Pasipriešinimo jègos koeficiento santykinès skaičiavimo paklaidos priklausomybė nuo sparno strèliškumo. NACA4415 sparnas, $\mathrm{Re}=2,1 \times 10^{6}, \mathrm{AR}=6,2$

Fig 4. Relative calculation error of wing drag force coefficient dependence on wing sweep. NACA4415 wing, $R e=2,1 \times 10^{6}$, $\mathrm{AR}=6,2$
5 ir 6 paveiksluose matyti, kad didejant sparno strèliškumui paklaidos didèja. Strèlinio sparno $\left(\phi=10^{\circ}\right)$ vidutiné atakos kampo keliamosios jègos koeficiento skaičiavimo paklaida, palyginti su stačiakampio sparno, padidèja $16,9 \%$, o pasipriešinimo jègos paklaida išauga $21,8 \%$ ir atitinkamai $29,4 \%$ bei $39,7 \%$, sparno strèliškumui padidejus iki $20^{\circ}$. Šiuose paveiksluose vertikaliosios linijos rodo paklaidos minimalią ir maksimalią reikšmę keičiantis sparno atakos kampui.

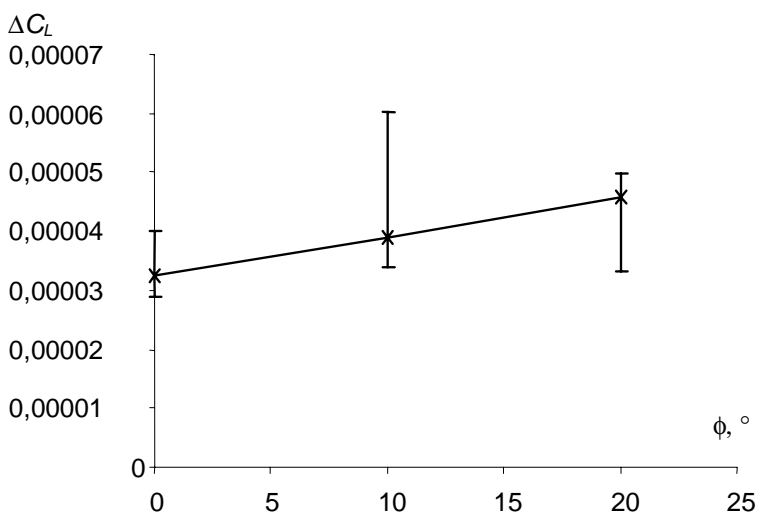

5 pav. Keliamosios jègos koeficiento vidutinès skaičiavimo paklaidos pokytis. NACA4415 sparnas, $\mathrm{Re}=2,1 \times 10^{6}, \mathrm{AR}=6,2$

Fig 5. Variation of average calculation error of wing lift force coefficient. NACA4415 wing $\operatorname{Re}=2,1 \times 10^{6}, \mathrm{AR}=6,2$

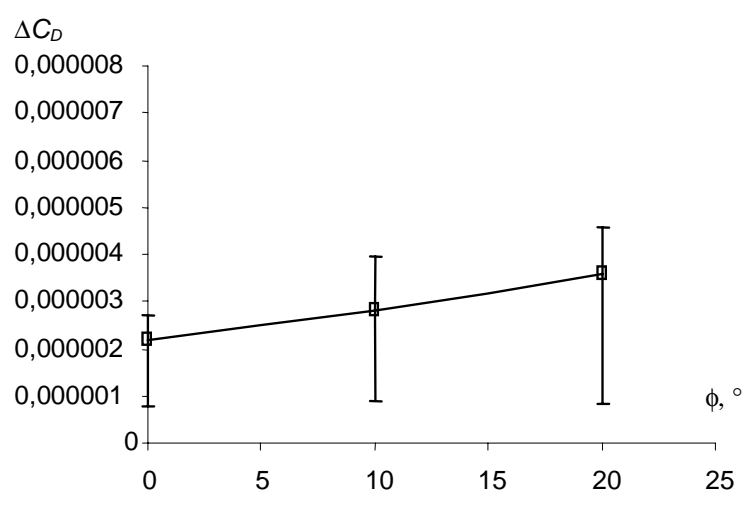

6 pav. Pasipriešinimo jègos koeficiento vidutinès skaičiavimo paklaidos pokytis. NACA4415 sparnas, $\mathrm{Re}=2,1 \times 10^{6}, \mathrm{AR}=6,2$

Fig 6. Variation of average calculation error of wing drag force coefficient. NACA4415 wing $\mathrm{Re}=2,1 \times 10^{6}, \mathrm{AR}=6,2$

\section{Išvados}

1. Didejjant atakos kampui absoliučioji keliamosios jègos koeficiento skaičiavimo paklaida keičiasi mažai.

2. Didejjant atakos kampui absoliučioji pasipriešinimo jëgos koeficiento skaičiavimo paklaida didèja.

3. Santykinès keliamosios jègos koeficientu skaičiavimo paklaidos mažèja, atakos kampui didejjant iki kritinio. 
4. Santykinès pasipriešinimo jègos koeficientu skaičiavimo paklaidos mažeja per visą atakos kampu diapazona.

5. Didejjant sparno strèliškumui skaičiavimo paklaidos (ir absoliučiosios, ir santykinès) didèja.

\section{Literatūra}

1. Pakalnis, E. Lift And Drag Force Calculation Methods Using Non-Linear Section Data. History And Resent Research. Aviation, Vol VIII, No 2. Vilnius: Technika, 2004, p. 9-13.

2. Barnes, J. P. Semi-Empirical Vortex Step Method for the lift and induced drag loading of 2D and 3D Wings. In: Society of Automotive Engineers, SAE Paper 975559, Oct 1997, p. 1-18.

3. Pakalnis, E.; Lasauskas, E.; Stankūnas, J. Method to Evaluate Nonlinear Effect in Calculation of a Finite Span Wing. In: Scientific proceedings of Riga Technical University. Vol 7, Transport and Engineering. Aviation Transport, 2003, p. 223-228.

4. Drela, M. XFOIL: An analysis and Design System for Low Reynolds Number Airfoils. In: Low Reynolds Number Aerodynamics, Springer-Verlag, New York, 1989, p. 1-12.

5. Jacob, K. Computation of the Flow around Wings with Rear Separation. Journal of Aircraft, No 21, 1984, p. 9798.
Jonas STANKŪNAS. Prof, Doctor Habil.

Antanas Gustaitis Aviation Institute of Vilnius Gediminas Technical University. Rodūnios kelias 30, LT-02187 Vilnius 38, Lithuania $(\mathrm{Ph}+3705$ 2744808, Fax + 3705 2745058), email: jnst@ai.vtu.lt.

Doctor Habil and Professor at the Dept of Avionic, Vilnius Gediminas Technical University, Lithuania. Member of editorial boards of 5 journals and collected research papers; member of Transport Council, Lithuanian Academy of Sciences. Advancement training in Great Britain, Canada, and Sweden. Author of 2 monographs and more than 100 scientific papers; author or co-author of 14 inventions. Participant of many intern conferences and research visits to the Aviation Institute of Riga Technical University of Latvia, Tartu Aviation College of Estonia, National Aviation University of Ukraine, Warsaw University of Technology, Rzeszow University of Technology of Poland, Brno University of Technology of Czech Republic.

Research interests: creation of signal tracts of super-wide band oxcillographic cathode - ray tubes and aviation technologies, development of microprocessor systems and automated designing.

Egidijus PAKALNIS. Doctoral student.

Vilnius Gediminas Technical University. Antanas Gustaitis Aviation Institute. Rodūnios kelias 30, LT-02187, Vilnius-38, Lithuania ( $\mathrm{Ph}+3705$ 2744809, Fax +370 5 2745058), e-mail: egidijus.pakalnis@tetrapak.com.

Master degree. At present Doctoral student of Dept of Aviation Mechanics, Antanas Gustaitis Aviation Institute. Author and coauthor of 9 scientific articles.

Research interests: low speed non-linear aerodynamics. 